\title{
Voriconazole In situ Gel for Ocular Drug Delivery
}

\author{
Puranik K M*, Tagalpallewar A A \\ Sinhgad Technical Education Society's, Sinhgad Institute of Pharmacy, Narhe, Pune, India
}

Received: April 09, 2015; Accepted: May 05, 2015; Published: May 29, 2015

*Corresponding author: Puranik K M, Sinhgad Technical Education Society's, Sinhgad Institute of Pharmacy, Narhe, Pune, India, Tel :

8149422492;

E-mail: kalyanipranav08@gmail.com

\begin{abstract}
Background: In-situ gelling systems are viscous polymerbased liquids that exhibit sol-to-gel phase transition on the ocular surface due to change in a specific physico-chemical parameter like temperature, ionic strength, or $\mathrm{pH}$. A major problem in ocular therapeutics is the attainment of optimal drug concentration at the site of action, which is mainly due to pre-corneal loss resulting in only a small fraction of the drug being ocularly absorbed. The effective dose administered can be altered by increasing the retention time of medication into the eye by using in situ gel forming systems, thereby preventing the tear drainage.
\end{abstract}

Aim: Formulation and evaluation of voriconazole ophthalmic insitu gel, based on sol-to-gel transition for ophthalmic delivery of an antifungal agent.

Method: Sodium alginate $(0.5,1.0,1.5 \%)$ in combination with HPMC K15M (0.1, 0.2, and $0.3 \%$ ) (HPMC K15M) was used. $3^{2}$ factorial design was adopted to optimize the variables. The formulations were evaluated for clarity, $\mathrm{pH}$ measurement, gelling capacity, drug content estimation, in vitro drug release, and ex-vivo corneal permeation studies using isolated goats cornea sterility test and for preservative effectiveness. The developed formulations showed sustained release of drug up to $8 \mathrm{hrs}$. The formulations were found to be non-irritating to cornea.

Conclusion: Formulation (F8) showed sustained release profile for voriconazole from a novel approach, ion sensitive insitu gellins system.

Keywords: In Situ, Voriconazole, Sodium Alginate, Factorial design, Histo pathology

\section{Introduction}

Fungal keratitis is an important cause of vision loss in developing countries characterized by a corneal epithelial defect and inflammation of the corneal stroma [17]. Currently, fungal keratitis remains a perplexing diagnostic challenge and a difficult management problem for ophthalmologists [7]. Various factors responsible for development of fungal karatitis includes ocular trauma, contamination of corneal lesions by soil and plant material, use of broad spectrum antibiotics and steroids use of contact lenses. Another important factor to be considered supportive to fungal karatitis are climatic conditions mainly temperate climate and tropical climate [10]. Early diagnosis of fungal keratitis and its treatment is important in preventing complications and loss of vision. Second-generation triazole i.e. Voriconazole is a new, broad-spectrum antifungal agent and is effective against Aspergillus spp and Fusarium spp [7, 11, 12].

Eye has a unique anatomy which restricts absorption of drug into the deep tissue [1]. For illness of eye topical administration is a well accepted route of administration [2]. Out of the total available marketed eye preparations, eye drops covers more than $90 \%$ of it [3]. Main problem associated with conventional eye drops is poor bioavailability [16] which is due different barriers such as lacrymal fluid-eye barriers and blood-ocular barriers [4] other reasons includes eye irritation caused by particle size and shape which induces lachrymation, naso lachrymal drainage system, enzymatic metabolism [5]. Different problems associated with conventional ophthalmic drug delivery system can be overcome by using insitu gel prepared from different polymers which are responsible phase transition in the cul-de-sac [6]

Current research concerns with ocular delivery of ion activated ophthalmic insitu gel of voriconazole using sodium alginate and HPMC K15M which would result in increase bioavailability and reduction in dose and dosing frequency. As voriconazole is hydrophobic drug so it becomes necessary to increase its water solubility. Vfend (powder for reconstitution) of Pfizer uses sulfobutyl ether- $\beta$-cyclodextrin (SBE- $\beta$-CD) to increase solubility of voriconazole $[17,18]$ Cyclodextrins is a group of cyclic oligosaccharides which are many times used to improve solubility of lipophilic drugs. HP- $\beta$-CD has a hydrophilic outer surface and a lipophilic central cavity which plays an important role to improve solubility [23]. Thus Hydroxypropyl$\beta$-cyclodextrin was used to prepare inclusion complex of voriconazole [2]. HPMC K15M is used as a viscosity enhancer to improve the residence time of gel on corneal surface. Sodium Alginate is a salt of alginic acid. It is a polysaccharide consisting $\beta$-D-mannuronic acid and $\alpha$-L-glucuronic acid residues joined by 1-4 glycosidic linkages isolated from strains of marine brown seaweed and algae [2,15]. Alginate forms stable gel by forming ionic cross-linking with divalent cation [13].

\section{Material and Method}

\section{Material}

Voriconazole was a gift sample from Matrix Laboratories, Hyderabad (India) .Sodium alginate, HPMC K15M, 
Hydroxypropyl- $\beta$-cyclodextrin were purchased from S. D. Fine Chemicals, Mumbai, India. All other ingredients and reagents were of analytical grade and were used as received.

\section{Method}

Inclusion complex of VCZ with HP- $\beta$-CD was prepared in a 1:3 molar ratio by kneading method.

Fourier transform infrared (FTIR) spectra of VCZ, HP- $\beta-C D$ and Voriconazole: HP- $\beta$-CD complex were taken with a FTIR 4100 , Jasco Japan using potassium bromide as blank between wavelengths of 400 and $4000 \mathrm{~cm}-1$.

Differential scanning Calorimetry (DSC) was carried out in the temperature range of 40 to $300^{\circ} \mathrm{C}$. By using Mettler Toledo DSC 1 Star System, Zurich Switzerland. At a heating rate of $10^{\circ} \mathrm{C}$ per min.

\section{Preparation of sodium alginate -HPMC insitu gelling system}

For preparation of Voriconazole insitu gel, sodium alginate and HPMC K15M was socked over night in distilled water. Drug solution was prepared by dissolving VCZ: HP- $\beta$-CD Complex in distilled water. Drug solution was added to polymer solution by stirring. Benzalkonium chloride $(0.01 \% \mathrm{w} / \mathrm{v})$ was added as a preservative to the previous solution. Sufficient amount of sodium chloride was added to this mixture to maintain isotonicity. Volume was made up to $10 \mathrm{ml}$ with distilled water. Prepared formulation was filled in a vial and subjected to autoclaving at $121^{\circ} \mathrm{C}$ for $20 \mathrm{mim}$.Nine batches were selected with varying proportions of HPMC K15M and Sodium alginate so as to optimize the voriconazole insitu gel as shown in table 1.

\section{Full factorial experimental design}

A $3^{2}$ factorial design was adopted to optimize the voriconazole insitu gel. Design was used to find out concentration of HPMC $\mathrm{K} 15 \mathrm{M}$ and Sodium alginate requires to form a gel which will give optimum release and proper viscosity to insitu gel. HPMC $\mathrm{K} 15 \mathrm{M}\left(\mathrm{X}_{1}\right)$ and the amount of Sodium alginate $\left(\mathrm{X}_{2}\right)$ were chosen as independent variables and $Y_{1}$ viscosity and $Y_{2}$ in-vitro drug release as dependent variables. In this design, two factors were evaluated each at three levels lower, middle and higher and the codes used were $-1,0,+1$ respectively.

In vitro gelling capacityGelling capacity of the formulations

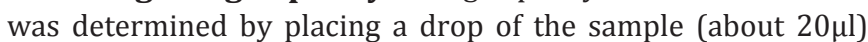
into a vial containing $2 \mathrm{ml}$ of $\mathrm{pH} 7.4$ simulated tear fluid (STF) equilibrated at $35 \pm 1^{\circ} \mathrm{C}$. The visual assessment of gel formation and dissolution with time was recorded. The compositions of STF were sodium chloride $0.67 \mathrm{~g}$, sodium bicarbonate $0.2 \mathrm{~g}$, calcium chloride $2 \mathrm{H}_{2} \mathrm{O} 0.008 \mathrm{~g}$, and purified water added to $100 \mathrm{ml}[1,19]$.

$(++)$ Gelation after few minute and disperse rapidly.

$(+++)$ Gelation immediately and remains for few hours.

(++++) Gelation immediately and remains for extended hours

\section{Determination of viscosity}

The developed insitu gel was poured into the small volume adaptor of the Brookfield viscometer (RVDV-II + PRO) and viscosity was recorded by increasing angular velocity gradually from $5,10,20,50$ and $100 \mathrm{rpm}$ with spindle number 21 . Viscosity was determined before at $25 \pm 1^{\circ} \mathrm{C}$ and after gelation at $35 \pm 1^{\circ} \mathrm{C}$.

\section{In vitro Drug Permeation}

In vitro drug permeation studies were carried out by putting the in situ gelling formulation on dialysis membrane between the donor and receptor compartments of glass modified Franz diffusion cell. The receptor compartment of a glass modified Franz diffusion cell was filled with freshly prepared simulated tear fluid. $1 \mathrm{ml}$ of test solution was placed on the dialysis membrane and opening of donor cell was sealed. The receptor fluid was kept at $37 \pm 0.5^{\circ} \mathrm{C}$ with constant stirring using a magnetic stirrer. Permeation study was continued for $8 \mathrm{hr}$, and samples were withdrawn at predetermined time interval of $1 \mathrm{hr}$ from receptor and same volume was replaced by fresh STF medium. The samples were further diluted and analyzed by RP-HPLC (Shimadzu SPD M20A,Softwere -LC Solution) The drug content was calculated using the equation generated from standard calibration curve and \% cumulative drug release (\% CDR) was calculated [22].

\section{Texture analysis}

Texture analyses provide information on mechanical

Table 1: Composition of different batches of voriconazole insitu gel.

\begin{tabular}{|c|c|c|c|c|c|c|}
\hline Sr. No. & $\begin{array}{c}\text { Voriconazole } \\
(\% \mathrm{w} / \mathrm{v})\end{array}$ & $\begin{array}{c}\text { Sodium alginate } \\
(\% \mathrm{w} / \mathrm{v})\end{array}$ & $\begin{array}{c}\text { HPMC K15M } \\
(\% \mathrm{w} / \mathrm{v})\end{array}$ & $\begin{array}{c}\text { BKC } \\
(\% w / v)\end{array}$ & $\begin{array}{c}\text { Sodium chloride } \\
(\% \mathrm{w} / \mathrm{v})\end{array}$ & $\begin{array}{l}\text { Distilled water } \\
\text { q.s. }(\mathrm{ml})\end{array}$ \\
\hline F1 & 0.25 & 0.5 & 0.1 & 0.01 & 0.9 & 10 \\
\hline F2 & 0.25 & 0.5 & 0.3 & 0.01 & 0.9 & 10 \\
\hline F3 & 0.25 & 0.5 & 0.5 & 0.01 & 0.9 & 10 \\
\hline $\mathrm{F} 4$ & 0.25 & 1 & 0.1 & 0.01 & 0.9 & 10 \\
\hline F5 & 0.25 & 1 & 0.3 & 0.01 & 0.9 & 10 \\
\hline F6 & 0.25 & 1 & 0.5 & 0.01 & 0.9 & 10 \\
\hline F7 & 0.25 & 1.5 & 0.1 & 0.01 & 0.9 & 10 \\
\hline F8 & 0.25 & 1.5 & 0.3 & 0.01 & 0.9 & 10 \\
\hline F9 & 0.25 & 1.5 & 0.5 & 0.01 & 0.9 & 10 \\
\hline
\end{tabular}


properties of samples, namely hardness, compressibility and adhesiveness. Texture profile analysis was conducted on optimized formulation using Brookfiled CT3 Texture Analyser. Strength of the gel was taken to be the hardness in compression. The test was performed by placing 20 gm sample. TA3/ 100 probe was used for analysis with pre-test speed $2 \mathrm{~mm} / \mathrm{s}$, test speed 0.5 $\mathrm{mm} / \mathrm{s}$ return speed of $0.5 \mathrm{~mm} / \mathrm{s}$. trigger lode $3 \mathrm{~g}$ [23]. Texture properties can be directly correlated with sensory parameters in vivo therefore, are essential in the development of a product with patient acceptability and compliance. Hardness measures force required to produce deformation of gels, while compressibility measures work required to achieve compression of product. Formulation with low hardness will be easy to remove from package and easy for administration [24].

\section{Sterility test for Voriconazole in situ gel}

Test was performed on previously sterilized formulation by direct inoculation method as per Indian Pharmacopoeia 2010 Voriconazole insitu gel was sterilized by autoclaving method at $121^{\circ} \mathrm{C}$ at $15 \mathrm{lb}$ pressure for 20 minutes. $2 \mathrm{ml}$ of formulation from test container was removed with a sterile pipette. Test liquid was aseptically transferred into fluid thioglycolate medium $(20 \mathrm{ml})$ and soyabean-casein digest medium $(20 \mathrm{ml})$ separately and was mixed. The inoculated media was incubated at $30^{\circ} \mathrm{C}$ to $35^{\circ} \mathrm{C}$ for fluid thioglycolate medium and $20^{\circ} \mathrm{C}$ to $25^{\circ} \mathrm{C}$ for soyabean-casein digest media for not less than 14 days [25].

\section{Preservative efficacy study}

Preservative efficacy was performed according to I.P. 2010 by challenging the formulation with Staphylococcus Aureous and Pseudomonas Aeruginosa No. of viable microorganisms were recorded after $0 \mathrm{hr}, 6 \mathrm{hrs}, 24 \mathrm{hrs}, 7$ days ,14 days, 24days.

\section{Isotonicity}

Isotonicity test was performed to prevent tissue damage or irritation of eye. Formulation was subjected to isotonicity testing (Osmomet 30)

\section{Ex- vivo corneal permeation studies}

Goat corneas were used to study the permeation across the corneal membrane. Whole eyeballs of goat were procured from a slaughter house and transported to laboratory in cold condition in normal saline maintained at $4 \stackrel{\circ}{\circ}$. The cornea were carefully removed along with a 5-6 $\mathrm{mm}$ of surrounding scleral tissue and washed with cold saline. The washed corneas were kept in cold freshly prepared solution of tear buffer of $\mathrm{pH}$ 7.4. The study was carried out by using Franz-diffusion cell in such a way that corneum side is continuously remained in an intimate contact with formulation in the donor compartment. The receptor

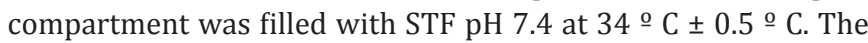
receptor medium was stirred on a magnetic stirrer. Permeation study was continued for $5 \mathrm{hr}$, and samples were withdrawn at a time interval of $1 \mathrm{hr}$ and analyzed for drug content on RP-HPLC. Receptor phase were replenished with an equal volume of STF $(\mathrm{pH}$ 7.4) at each time interval. The percent drug released was plotted against time [18].

\section{Antifungal Studies}

The antifungal efficiency and prolonged effect of selected sustained release in situ gel of voriconazole formulation was carried out on Candida albicans and Asperigillus fumigatus species. The nutrient agar medium was prepared by dissolving saboured dextrose in hot distilled water and media was autoclaved at $121^{\circ} \mathrm{C}$ for $15 \mathrm{~min}$. By using diffusion method test organisms were previously seeded $(10 \mathrm{CFU} / \mathrm{mL}$.) in the nutrient agar medium. Wells of $10 \mathrm{~mm}$ diameter were punched out using a steel borer. Aliquot test samples were poured into petri dish containing nutrient agar medium using micro pipette. The plates were left for $30 \mathrm{~min}$ and then incubated at $25^{\circ} \mathrm{C}$ for $24 \mathrm{hr}$. Diameters of zone of inhibition for Candida albicans and Aspergillus fumigatus were measured after $24 \mathrm{hr}$ [1].

\section{Histopathology study}

Irritation potential was evaluated using fresh goat cornea, incubated with Voriconazole in-situ gel. At stipulated incubation time, the cornea was removed, washed with phosphate buffered saline, and immediately fixed with $8 \%(\mathrm{w} / \mathrm{w})$ formalin solution. The tissue was dehydrated with an alcohol gradient, kept in melted paraffin and solidified in block form. Cross-sections was cut, stained with haematoxyline and eosine, and microscopically observed for modifications [26].

\section{Accelerated stability study}

Formulation was subjected to elevated temperature and humidity conditions of $25 \pm 1^{\circ} \mathrm{C} / 60 \% \mathrm{RH}, 30 \pm 1^{\circ} \mathrm{C} / 65 \% \mathrm{RH}$ and 40 $\pm 2 \mathrm{oC} / 75 \pm 5 \% \mathrm{RH}$. Samples were withdrawn at the end of 0 , 30,60 and 90 days and evaluated for $\mathrm{pH}$, appearance and \% drug content.

\section{Results and discussion}

\section{Full factorial experimental design}

Design Expert 8 software was used to study the effect of independent variable on response. Different models such as linear, 2FI, Quadratic and Cubic which fit well was suggested by software and was tested for analysis of variance (ANOVA). For every dependent variable regression polynomial was calculated, contour plots and 3D surface graphs were obtained for each individual dependent variable i.e. viscosity and drug release. Mathematical models were generated and expressed as equation 1-2. $X_{1}$ and $X_{2}$ are the main effects which represent the average result of changing one factor at a time from its low to high value and $X_{1} X_{2}$ are interaction terms which show how the response changes when two factors are simultaneously changed. Nonlinearity is investigated by polynomial terms $\mathrm{X}_{1}^{2}$ and $\mathrm{X}_{2}^{2}$. Experimental design layout of voriconazole insitu gel is shown in table 2.

\section{HPßCD-Voriconazole complex characterization}

Prepared HP- $\beta$-CD-Voriconazole complex was characterized by FT-IR and DSC.

Comparing IR spectra of voriconazole (Figure1.a), HP- $\beta$-CD (Figure1.b) and voriconazole: HP- $\beta$-CD complex (Figure1.c) it 
Table 2: Experimental design layout of voriconazole insitu gel.

\begin{tabular}{|c|c|c|c|c|c|c|c|}
\hline \multirow[t]{2}{*}{ Sr. No. } & \multirow[t]{2}{*}{ Batch } & \multicolumn{2}{|c|}{ Coded levels of variables } & \multirow{2}{*}{$\begin{array}{c}\text { \% drug release } \\
\left(\mathrm{Y}_{1}\right)\end{array}$} & \multirow[t]{2}{*}{$\begin{array}{c}\text { viscosity (cps) } \\
\text { (Y2) }\end{array}$} & \multicolumn{2}{|c|}{ Actual levels of variables } \\
\hline & & $\begin{array}{l}\text { Factor } \mathrm{X}_{1} \text { Sodium } \\
\text { alginate }\end{array}$ & $\begin{array}{c}\text { Factor } \mathrm{X}_{2} \text { HPMC } \\
\text { K15 M }\end{array}$ & & & $\begin{array}{c}\text { Sodium alginate } \\
\left(\mathrm{X}_{1}\right) \\
(\% \mathrm{w} / \mathrm{v})\end{array}$ & $\begin{array}{c}\text { HPMC K15M } \\
\left(\mathrm{X}_{2}\right) \\
(\% \mathrm{w} / \mathrm{v})\end{array}$ \\
\hline 1 & $\mathrm{~F} 1$ & -1 & -1 & 89.63 & 1260 & 0.5 & 0.1 \\
\hline 2 & F2 & -1 & 0 & 97.03 & 3150 & 0.5 & 0.3 \\
\hline 3 & F3 & -1 & 1 & 94.46 & 6138 & 0.5 & 0.5 \\
\hline 4 & $\mathrm{~F} 4$ & 0 & -1 & 98.89 & 2200 & 1 & 0.1 \\
\hline 5 & F5 & 0 & 0 & 96.12 & 3900 & 1 & 0.3 \\
\hline 6 & F6 & 0 & 1 & 93.98 & 6475 & 1 & 0.5 \\
\hline 7 & F7 & 1 & -1 & 98.37 & 3150 & 1.5 & 0.1 \\
\hline 8 & F8 & 1 & 0 & 94.67 & 5825 & 1.5 & 0.3 \\
\hline 9 & F9 & 1 & 1 & 93.23 & 8025 & 1.5 & 0.5 \\
\hline
\end{tabular}

was observed that the absorption intensity of group appearing in $1589 \mathrm{~cm}^{-1}$ (Aromatic C=C Stretch) in voriconazole was absent in inclusion complex, so it can be deduced that voriconazole was included into the cavity of HP- $\beta$-CD .as shown in Figure 1.c

According to the DSC results it appears that the DSC curves of the inclusion complex, (Figure 2 c)Voriconazole (Figure $2 \mathrm{a}$ ) and HP- $\beta$-CD (Figure $2 \mathrm{~b}$ ) are different. The DSC results demonstrated an endothermic peak for voriconazole and HP- $\beta-\mathrm{CD}$ at $131.30^{\circ} \mathrm{C}$ and $88.06^{\circ} \mathrm{C}$, respectively. Inclusion complex showed a wide endothermic peak around $63.92^{\circ} \mathrm{C}$. The disappearance of endothermic peaks of voriconazole and appearance of another endothermic peak might indicate formation of inclusion complex between voriconazole and HP- $\beta$-CD.complex.

\section{Gelling capacity}

All the formulations were slightly yellow in color and were found to be clear. The $\mathrm{pH}$ of the formulations was in the range of 6.7 to 7.2 Observations are listed in table 3

++ indicates Phase transition within $60 \mathrm{sec}$ and gel structure stable for $6 \mathrm{hrs}$,
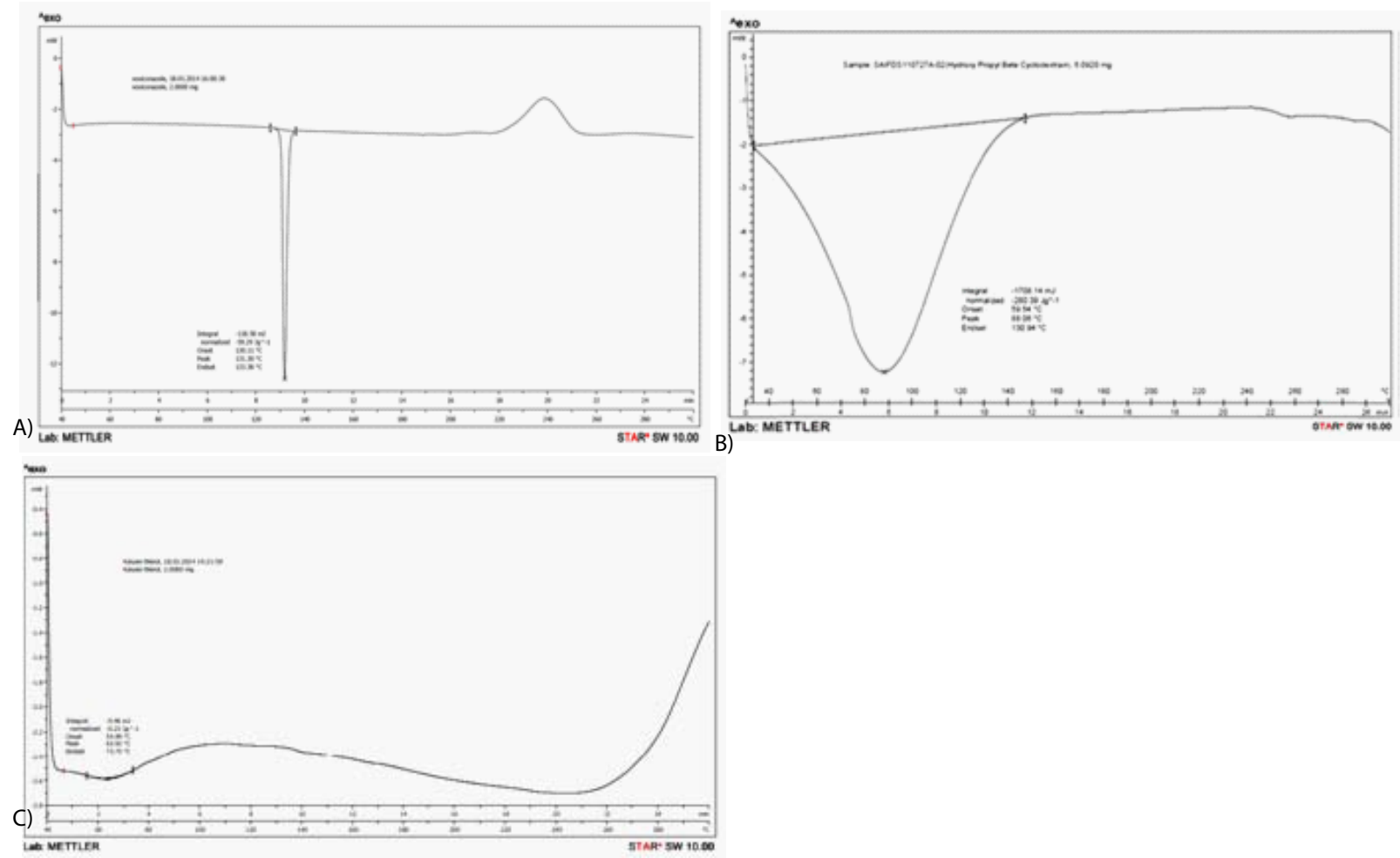

Figure 1: (a) DSC Thermogram of Voriconazole, (b) DSC Thermogram of HP- $\beta-C D$, (c) DSC Thermogram of Voriconazole with all excipients. 

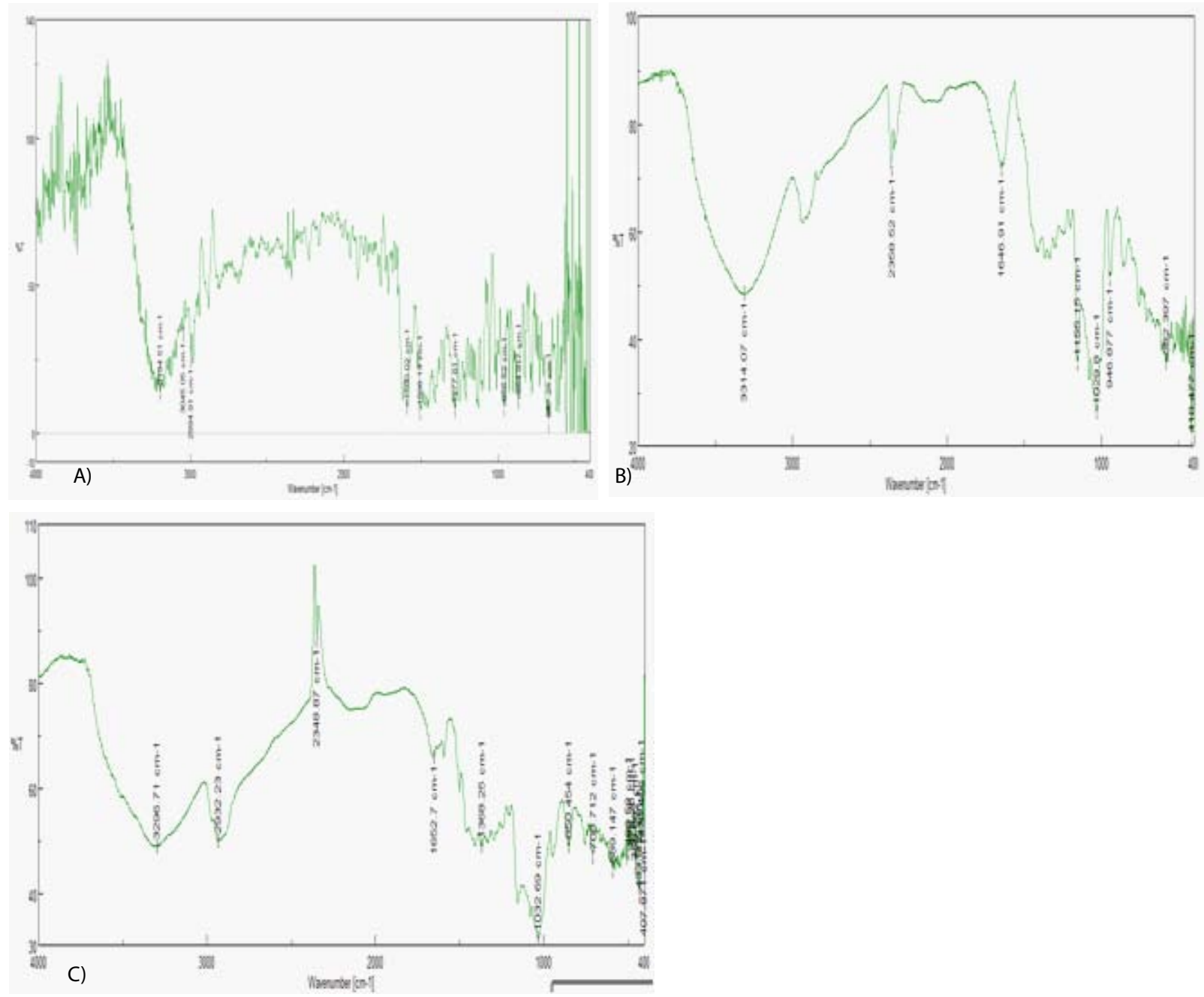

Figure 2: (a) FTIR Spectra of Voriconazole (b) FTIR spectra: HP- $\beta$-CD (c) FTIR spectra Voriconazole - HP- $\beta$-CD Complex.

Table 3: Evaluation of the formulation.

\begin{tabular}{|c|c|c|c|c|c|c|c|}
\hline Batch code & $\begin{array}{c}\text { Voriconazole } \\
(\% w / v)\end{array}$ & $\begin{array}{l}\text { Sodium } \\
\text { alginate } \\
(\% w / v)\end{array}$ & $\begin{array}{c}\text { HPMC K15M } \\
(\% w / v)\end{array}$ & Appearance & Clarity & pH & $\begin{array}{c}\text { Gelling } \\
\text { capacity }\end{array}$ \\
\hline F1 & 0.25 & 0.5 & 0.1 & Slightly Yellow & Clear & 6.9 & ++ \\
\hline $\mathrm{F} 2$ & 0.25 & 0.5 & 0.3 & Slightly Yellow & Clear & 6.7 & ++ \\
\hline F3 & 0.25 & 0.5 & 0.5 & Slightly Yellow & Clear & 7.2 & ++ \\
\hline $\mathrm{F} 4$ & 0.25 & 1 & 0.1 & Slightly Yellow & Clear & 6.8 & +++ \\
\hline F5 & 0.25 & 1 & 0.3 & Slightly Yellow & Clear & 7.0 & +++ \\
\hline F6 & 0.25 & 1 & 0.5 & Slightly Yellow & Clear & 7.2 & +++ \\
\hline F7 & 0.25 & 1.5 & 0.1 & Slightly Yellow & Clear & 6.8 & ++++ \\
\hline F8 & 0.25 & 1.5 & 0.3 & Slightly Yellow & Clear & 7.2 & ++++ \\
\hline F9 & 0.25 & 1.5 & 0.5 & Slightly Yellow & Clear & 6.9 & ++++ \\
\hline
\end{tabular}

+++ indicates Phase transition within $40 \mathrm{sec}$ and gel structure stable for more than $6 \mathrm{hrs}$,

++++ indicates Phase transition within $30 \mathrm{sec}$ and gel structure remain for long time.

\section{Determination of viscosity}

Initially formulation was free flowing which after coming in contact with divalent ions $\left(\mathrm{Ca}^{++}\right)$it shows increase in viscosity. Viscosity was determined Brookfield RVDV-II + PRO viscometer with spindle number 21 as shown in Figure 3

Viscosity of formulations at $20 \mathrm{rpm}$ was used for optimization. 
On applying factorial design, linear model was suggested by software for response Y2 and found to be significant with model $F$ value of 160.63 , $p$ value $<0.0001$ and $R^{2}$ value of 0.98 which implied that model was significant. And there was only a $0.01 \%$ chance that a "Model F-Value" this large could occur due to noise. Values of "Prob > F" less than 0.05 for each term was obtained which indicated that every model term was significant. In this case X1 have significant effect on formulation. The model for response Y2 (viscosity) is as follows:

$$
\mathrm{Y}=4498.67+2336.33(\mathrm{X} 1)+1014.50(\mathrm{X} 2)
$$

Effect of factor $\mathrm{X} 1$ and factor $\mathrm{X} 2$ can be further interpreted with the help of contour plot and 3D

Response surface plots as shown in Figure 4 (a), (b)

\section{In vitro Drug release}

Voriconazole in situ gels were subjected for in vitro diffusion studies using Franz diffusion cell. The cumulative percent release of voriconazole as function of time is shown in Figure 5. Optimized batch showed $94.67 \%$ release of drug up to $8 \mathrm{hr}$.

On applying factorial design, the Quadratic model was suggested by software for response $\mathrm{Y} 1$ and found to be significant with model $F$ value of 15.39 , $p$ value 0.0239 and $R^{2}$ value of 0.96 which implied that model was significant. And there was only a $0.01 \%$ chance that a "Model F-Value" this large could occur due to noise. Values of "Prob > F" less than 0.05 for each term was obtained which indicated that every model term was significant. In this case $\mathrm{X}_{1}$ and $\mathrm{X}_{1}^{2}$ were significant model terms. TIn this case $\mathrm{X} 1$ have significant effect on drug release. The model for response $\mathrm{Y} 1$ (\% drug release) is as follows:

$$
\left(\mathrm{X}_{2}^{2}\right)
$$$$
\mathrm{Y}=83.51-2.26\left(\mathrm{X}_{1}\right)-0.60\left(\mathrm{X}_{2}\right)+1.18\left(\mathrm{X}_{1} \mathrm{X}_{2}\right)+1.85\left(\mathrm{X}_{1}^{2}\right)-0.35
$$

Effect of factor X1 and factor X2 can be further interpreted with the help of contour plot and 3D response surface plots. Figure $6(\mathrm{a}),(\mathrm{b})$

As discuss in experimental design formulation which shows desired viscosity with optimum drug release was selected as optimized formulation. Batch F8 showed $5825 \mathrm{cp}$ viscosity with $94.67 \%$ drug release at $8^{\text {th }} \mathrm{hr}$. was consider as optimized batch and was used for further evaluations. Table 4 gives Different kinetic models for release of voriconazole form ion sensitive in situ forming gel preparations.

Regression coefficient $\left(\mathrm{R}^{2}\right)$ values were obtained from the plots and Korsemeyer-Peppas model was found to be suitable to explain release kinetic of drug where $\mathrm{R}^{2}$ was 0.9895

\section{Drug content uniformity}

Drug content uniformity was determined in triplicate by randomized sampling from same container of optimized formulation. It was found as $98.08 \%, 98.29 \%$ and $98.35 \%$.

\section{Texture profile}

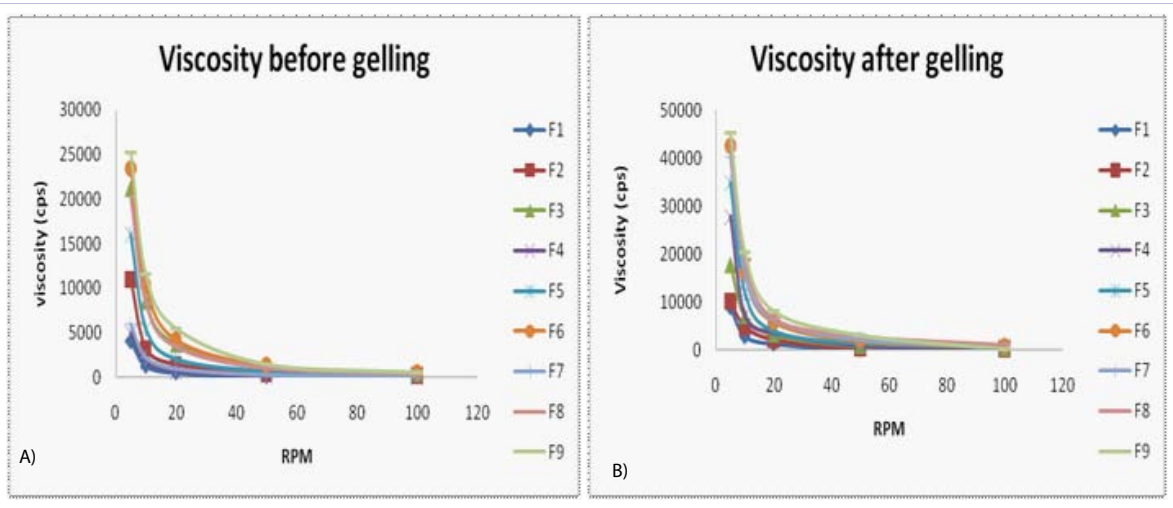

Figure 3: Comparative viscosity of all batches of in situ gel (a) Before gelling and (b) After gelling.
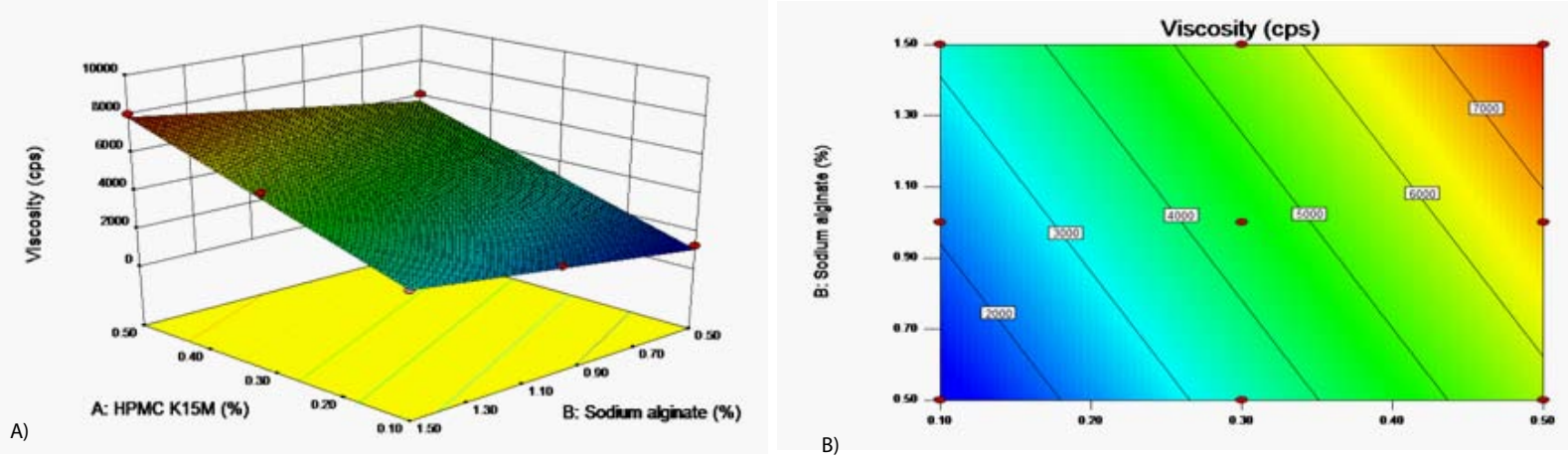

Figure 4: Two dimensional contour plot (a), three dimensional (3D) response surface plots for response Y1 (b) for viscosity. 


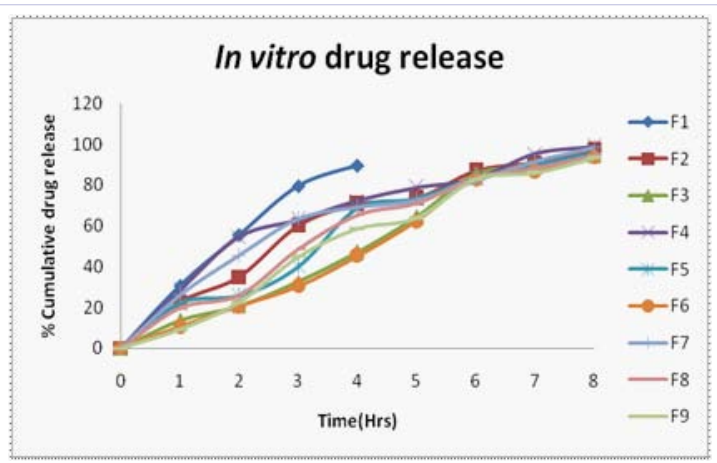

Figure 5: In-vitro drug release.
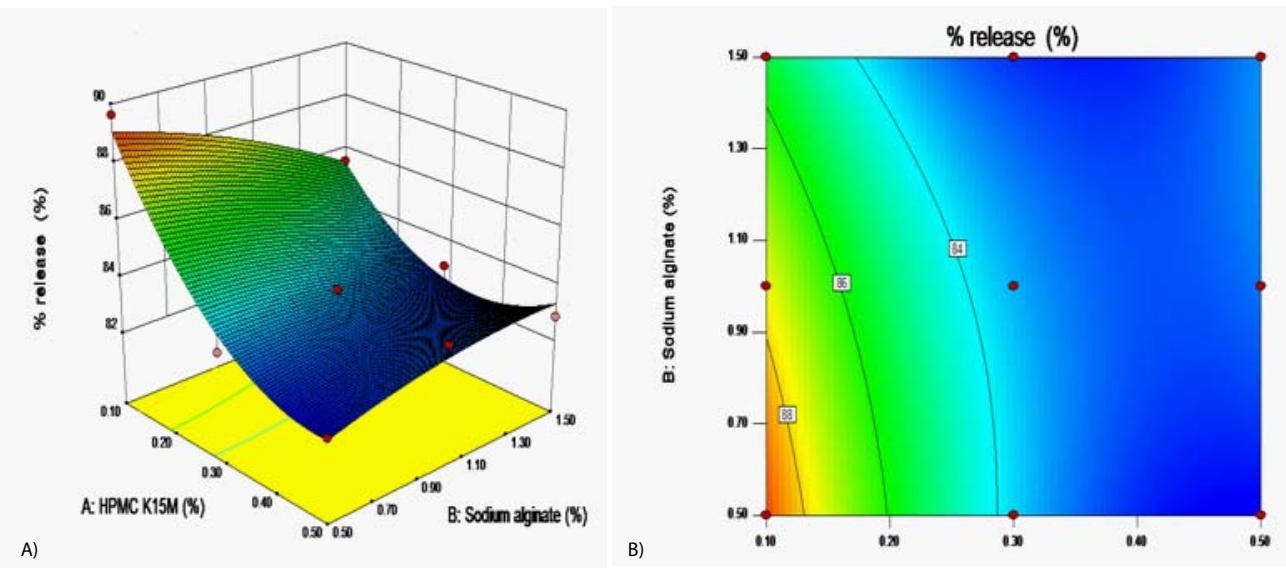

Figure 6: Two dimensional contour plot (a), three dimensional (3D) response surface plots for response Y1 (b) for \% drug release.

Gelling strength of in situ gel was measured in terms of hardness. Before gelling hardness was found to be $17 \mathrm{~g}$ while after gelling it was found to be $20 \mathrm{~g}$ as depicted in Figure 7(a), (b) respectively. This change in hardness values after and before gelling indicates that gelling strength of prepared formulation at physiological condition is more. Hence, formulation can be easily placed into the eye and it will remain for longer time in the eye.

\section{Sterility test}

There was no appearance of turbidity and hence no evidence of microbial growth; when optimized formulations was incubated for not less than 14 days at $30-35^{\circ} \mathrm{C}$ in case of fluid thioglycollate medium and $20-25^{\circ} \mathrm{C}$ in the case of soya-bean casein digest medium. Thus preparation examined passes the test for sterility.

\section{Preservative Efficacy Studies}

Preservative efficacy studies were carried out on batch F8 formulation, observations are shown in Table 5. No microbial growth was observed at the end of 28 days of inoculation so formulation passes the preservative efficacy test as per I.P. 2010.

\section{Isotonicity studies}

Isotonicity study was carried out by using Osmomet - 30 . Optimized batch was subjected for tonicity evaluation. Tonicity was found to be $0.2950 \mathrm{smol} / \mathrm{kg}$ i.e. $295 \mathrm{~m} \mathrm{Osmol} / \mathrm{kg}$ which is within the acceptable limit (290-310 m Osmol/kg).
Table 4: Different kinetic models for release of voriconazole form ion sensitive in situ forming gel preparations.

\begin{tabular}{|c|c|}
\hline Kinetic model & $\mathbf{R}^{2}$ \\
\hline Zero-order & 0.9055 \\
\hline First-order & 0.9878 \\
\hline Higuchi & 0.9292 \\
\hline Korsemeyer-Peppas & 0.9895 \\
\hline Hixon-Crowel cube root & 0.9840 \\
\hline
\end{tabular}

\section{Ex-vivo drug permeation studies}

Ex-vivo drug permeation study was carried out to check the permeability of voriconazole through goat cornea. To simulate the ocular condition, goat corneas were used for permeation studies and the experiment was conducted for $5 \mathrm{hr}$. In goat corneas permeation studies, the formulation F8 showed $51.93 \%$ drug release at the end of $5 \mathrm{hr}$. Cumulative drug release is shown in Figure 8

Corneal permeability was calculated by using equation No. 3 and 4 .

$$
\begin{aligned}
& \mathrm{P}_{\text {app }}=\mathrm{J}_{\text {ss }} / \mathrm{C}_{\mathrm{d}} \\
& \mathrm{D}=\mathrm{P}_{\text {app }} \times \mathrm{L} / \mathrm{K}
\end{aligned}
$$



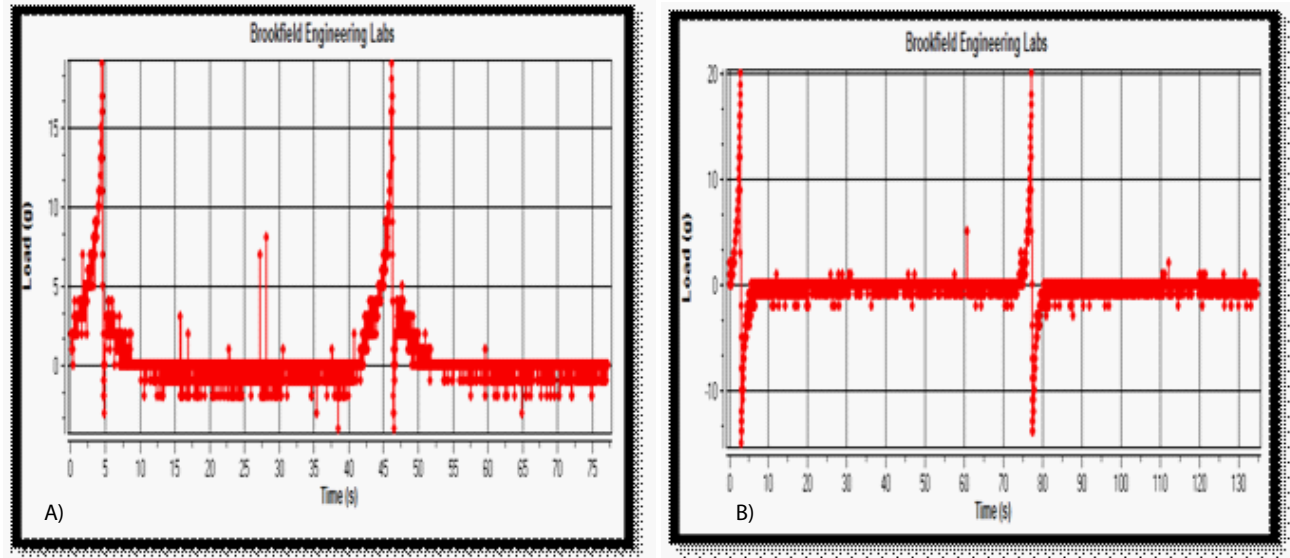

Figure 7: (a) Hardness before gelling. (b) Hardness after gelling.

Where; $\mathrm{P}_{\text {app - }}$ apparent permeability coefficient,

Jss-steady state flux

$\mathrm{C}_{\mathrm{d} \text { - }}$ initial donor chamber concentration of drug.

D - Steady state diffusion coefficient,

L - Diffusion path length,

K- Partition coefficient of drug.

Jss was calculated by plotting the cumulative amount of Voriconazole $(\mu \mathrm{g})$ permeated per unit area against time (hr) and slope of the linear portion of the curve was considered as steady state flux. The apparent permeability coefficient (Papp), steady state flux (Jss) and the steady state diffusion coefficient (D) of Voriconazole was found to be $144.92 \times 10^{-2} \mathrm{~cm} \mathrm{~h}^{-1}, 36.23 \mathrm{~cm}^{-2} \mathrm{~h}^{-1}$ and $79.62 \times 10^{-2} \mathrm{~cm}^{2} \mathrm{~h}^{-1}$, respectively.

\section{Antifungal efficacy}

Table 5: Microbial count during preservative efficacy study.

\begin{tabular}{|l|c|c|c|c|c|c|}
\hline Microorganism & $\mathbf{0 h r}$ & $\mathbf{6 h r}$ & $\mathbf{2 4 h r}$ & 7days & 14days & 28days \\
\hline S. aureus & 223 & 5 & 0 & 0 & 0 & 0 \\
\hline P. aerogenosa & 463 & 9 & 0 & 0 & 0 & 0 \\
\hline
\end{tabular}

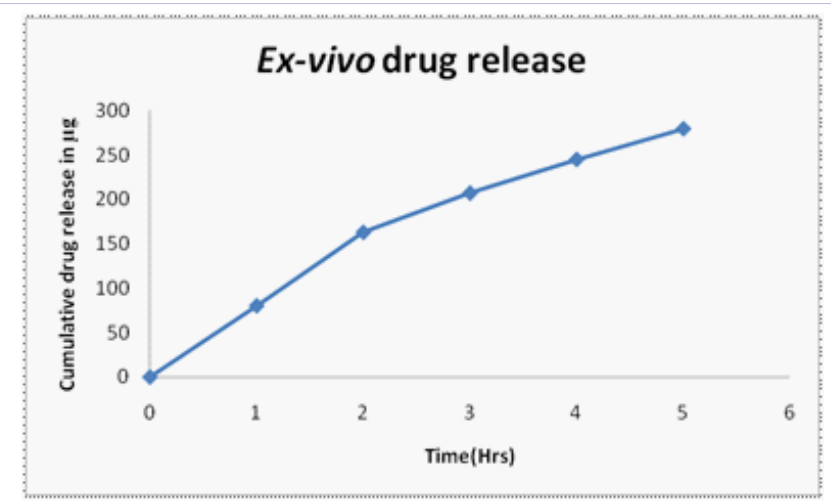

Figure 8: Ex-vivo drug release.
The antifungal efficiency of the selected voriconazole formulation was evaluated against organisms including Candida albicans and Aspergillus fumigatus. The mean diameters of zone of inhibition with Candida albicans and Aspergillus fumigates are depicted in Table 6 . The study indicated that the voriconazole retained its antifungal efficacy even after formulated as an in situ gelling system.

\section{Histopathology study}

Goat cornea confirmed the presences of normal ocular surface tissue maining its normal morphological structures in both control and test. Epidermal layer displayed normal characteristics. There was no evidence for any damage to the normal structure. In positive control (treatment with 0.1\% SDS) there was alteration in corneal epidermal layer (Figure 9).

\section{Accelerated stability study as per ICH Guidelines}

Stability study was carried out as per ICH guidelines on optimized voriconazole in situ gel for 3 months. It was observed that in situ gelling formulations remained stable at $25 \pm 1^{\circ} \mathrm{C} / 60 \%$ $\mathrm{RH}, 30 \pm 1^{\circ} \mathrm{C} / 65 \% \mathrm{RH}$ and $40 \pm 1^{\circ} \mathrm{C} / 75 \% \mathrm{RH}$. The results obtained are shown in Table 7.

\section{Conclusions}

In this work sodium alginate and HPMC $\mathrm{K} 15 \mathrm{M}$ was used to formulate ion sensitive insitu gelling system for Voriconazole, to increase ocular residence time and to reduce frequency of dose. Voriconazole is a lipophilic drug with a low $\mathrm{pH}$ dependent aqueous solubility; it is encapsulated in HP- $\beta$-CD in order to increase the solubility and stability of Voriconazole in aqueous solutions. Various formulations of different proportions of polymers were prepared and optimization was carried out by using Design expert 8.0 software. Optimized batch F8 was evaluated for exvivo study, preservative efficacy studies, histopathological study, and texture analysis, sterility test as per I.P. 2010 and accelerated stability studies as per ICH guideline.

Physical evaluation of the in-situ gels indicates that, the biological environment has a great influence on the performance 
Table 6: Antifungal efficacy of voriconazole in situ gel.

\begin{tabular}{|c|c|c|c|}
\hline Species & Std & \multicolumn{2}{|c|}{$\begin{array}{c}\text { Zone of inhibition }(\mathbf{m m}) \\
\text { (\% efficiency) }\end{array}$} \\
\hline $\begin{array}{c}\text { Candida albicans } \\
\text { (ATCC 10231) }\end{array}$ & 40 & $34(85 \%)$ & 0 \\
\hline $\begin{array}{c}\text { Aspergillus } \\
\text { fumigates (ATCC } \\
\text { 1022) }\end{array}$ & 68 & $60(88 \%)$ & 0 \\
\hline $\begin{array}{c}\text { Std-Voriconazole } \\
\text { Test 1- Formulation. } \\
\text { Test 2 - Placebo }\end{array}$ & & \\
\hline
\end{tabular}

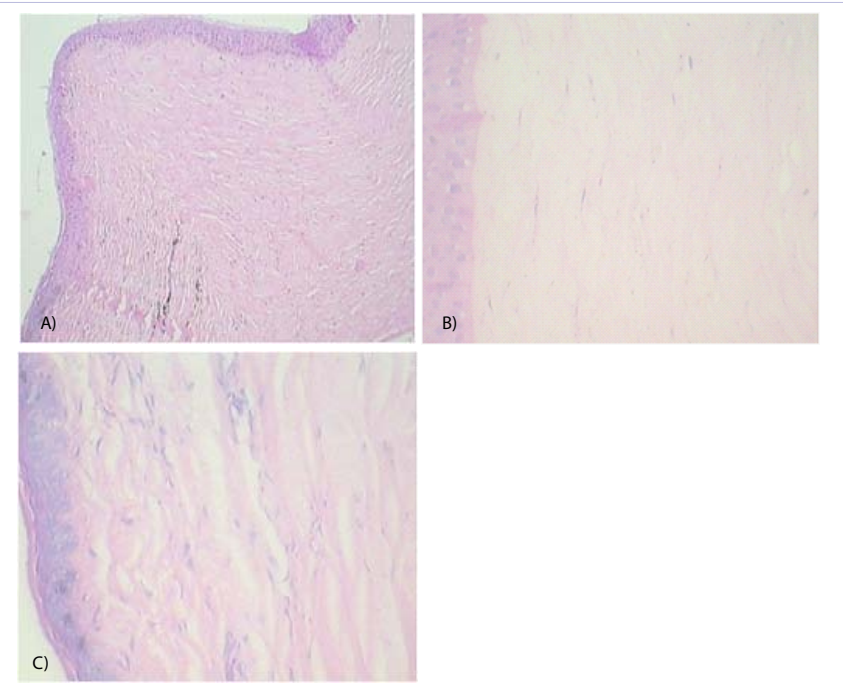

Figure 9: Histopathological sections of goat cornea (Magnification 40 $\mathrm{X}$ ) (a) negative control (untreated cornea) (b) test sample (treated with voriconazole insitu gel) (c) Positive control (cornea treated with $0.1 \%$ SDS).

\begin{tabular}{|c|c|c|c|c|}
\hline \multicolumn{3}{|c|}{ Table 7: Stability study. } \\
$\begin{array}{c}\text { Time } \\
\text { (month) }\end{array}$ & Temperature $\backslash \% \mathbf{R H}$ & \multicolumn{3}{|c|}{ Parameter } \\
\hline & & $\mathbf{p H}$ & $\begin{array}{c}\text { Appear- } \\
\text { ance }\end{array}$ & $\begin{array}{c}\text { \%Drug con- } \\
\text { tent }\end{array}$ \\
\hline & $25 \pm 1^{\circ} \mathrm{C} / 60 \pm 5$ & 6.9 & + & 99.02 \\
\hline $\mathbf{1}$ & $30 \pm 1^{\circ} \mathrm{C} / 65 \pm 5$ & 6.9 & + & 99.23 \\
\hline & $40 \pm 2^{\circ} \mathrm{C} / 75 \pm 5$ & 7.0 & + & 98.85 \\
\hline & $25 \pm 1^{\circ} \mathrm{C} / 60 \pm 5$ & 6.8 & + & 98.56 \\
\hline $\mathbf{2}$ & $30 \pm 1^{\circ} \mathrm{C} / 65 \pm 5$ & 6.8 & + & 98.12 \\
\hline & $40 \pm 2^{\circ} \mathrm{C} / 75 \pm 5$ & 6.7 & + & 97.78 \\
\hline & $25 \pm 1^{\circ} \mathrm{C} / 60 \pm 5$ & 6.8 & + & 98.46 \\
\hline $\mathbf{3}$ & $30 \pm 1^{\circ} \mathrm{C} / 65 \pm 5$ & 6.8 & + & 98.32 \\
\hline & $40 \pm 2^{\circ} \mathrm{C} / 75 \pm 5$ & 6.7 & + & 97.67 \\
\hline & + Sign indicates no change in formulation \\
\hline
\end{tabular}

of the formulation. In-vitro release results showed that, formulation succeeded to prolong the drug release from the sodium alginate and HPMC K15M based ion sensitive insitu gel. It was found that F8 has $94.67 \%$ drug release at 8 hrs with desired viscosity $5825 \mathrm{cps}$. The results showed successful formulation of sustained release profile of voriconazole from a novel formulation approach using ion sensitive insitu gelling system.

\section{References}

1. Rathapon A, Suthira T, Asira F, Sukitaya V. Optimization and evaluation of thermoresponsive diclofenac sodium ophthalmic in situ gels. Int. J. Pharm. 2011;411(1-2):128-135. doi: 10.1016/j.ijpharm.2011.03.054.

2. Basaran B and Bozkir A. Thermosensitive and $\mathrm{pH}$ induced in situ ophthalmic gelling system for ciprofloxacin hydrochloride:hydroxypropyl- $\beta$-cyclodextrin complex. Acta Poloniae Pharmaceutica -Drug Research. 2012;69(6):1137-1147.

3. Kumar M and Kulkarni GT. Recent advances in ophthalmic drug delivery system. Int. J. Pharm. Pharm Sci. 2012;4(1):387-394.

4. Tangri P, Khurana S. Basics of ocular drug delivery systems. Int.J.Res. Pharm.Bio.Sci. 2011;2(4):1541-1551.

5. Willoughby CE, Ponzin D, Ferrari S, Lobo A, Landau K and Omidi Y. Anatomy and physiology of the human eye: effect of mucopolysaccharidoses disease on structure and function-a review. Cli. Exp.Opth. 2010;38(1):2-11. Doi:10.1111/j1442-9071.2010.02363.x

6. El-Kamel AH. In vitro and in vivo evaluation of Pluronic F127based ocular delivery system for timolol maleate. Int. J. Pharm. 2002;241(1):47-55.

7. Dong X, Xie L, Shi W. Treatment of fungal keratitis by penetrating keratoplasty . Br. J. Ophthalmol. 2001;85:1070-1074. doi:10.1136/ bjo.85.9.1070.

8. Tanure MA, Cohen EJ, Sudesh S, Rapuano CJ, Laibson PR. Spectrum of fungal keratitis at Wills Eye Hospital, Philadelphia, Pennsylvania. Cornea. 2000;19(3):307-312.

9. Lixin X, Xiaoguang D, Weiyun S. Treatment of fungal keratitis by penetrating Keratoplasty. Br. J Ophthalmol. 2001;85:1070-1074. doi: 10.1136/bjo.85.9.1070

10. Saha S, Banerjee D, Khetan A, Sengupta J. Epidemiological profile of fungal keratits in urban population of West Bengal,India. Oman J Ophthalmol. 2009;2(3):114-118. doi: 10.4103/0974-620X.57310

11. Kim JE, Perkins SL, Harris GJ. Voriconazole treatment of fungal scleritis and epibulbar abscess resulting from scleral buckle infection. Arch Ophthalmol. 2003;121(5):735-737.

12. Klont RR, Eggink CA, Rijs AJ, Wesseling P, Verweij PE. Successful treatment of Fusarium keratitis with cornea transplantation and topical and systemic voriconazole. Clin Infect Dis. 2005;40(12):110112.

13. Verma L, Sakir M, Singh N, Mehra R, Sidharth Mehan. Development of phase change solutions for ophthalmic drug delivery based on ion activated and $\mathrm{pH}$ induced polymers. Int J pharma professional's res. 2010;1(2):127-134

14. Bhalerao AV, Singh SS. In situ gelling ophthalmic drug delivery system for glaucoma. Int. J. Pharma and Bio Sciences. 2011;2(2):7-14

15. Brownlee IA, Allen A, Pearson JP, Dettmar PW, Havler ME, Atherton MR, et.al. Alginate as a source of dietary fiber. Critical reviews in food science and nutrition. 2005;45(6):497-510. doi: $10.1080 / 10408390500285673$

16. Kavitha K, Rajas NJ. Sustained ophthalmic delivery of levofloxacin hemihydrates from an ion activated in situ gelling system. Int. J. 
PharmTech Research. 2011;3(2):702-706.

17. Malhotra S, Khare A, Grover K, Singh I, Pawar, P. Design and evaluation of voriconazole eye drops for the treatment of fungal keratitis. Journal of Pharmaceutics. 2014;1-9. doi.org/10.1155/2014/490595

18. Vodithala S, Khatry S, Shastri N, Sadanandam M. Development and evaluation of thermoreversible ocular gels of ketorolac tromethamine. Int. J. Biopharm. 2010;1(1):39-45.

19. Shetty NG, Charyulu RN, Marina K, Shastry CS. Investigation of $\mathrm{pH}$ dependant in situ gel forming solution of Imidazoline drug for ocular administration. Int. J. Res.Pharm.Sci. 2012;3(1):120-126.

20. Katarina E, Johan C, Roger P. Rheological evaluation of poloxamer as an in situ gel for ophthalmic use. Eur J Pharm Sci. 1998;6(2):105-112.

21. Pawar P, Kashyap H, Malhotra S, Sindhu R. Hp- $\beta$-CD-Voriconazole in situ gelling system for ocular drug delivery: In vitro, stability, and antifungal activities assessment. BioMed Research International. 2013;1-9. doi.org/10.1155/2013/341218.
22. Rathore K. In- situ gelling ophthalmic drug delivery system: An overview. Int J Pharmacy and pharmaceutical sciences. 2010;2(4):3034.

23. Gawad H, OA. Soliman, SA Barker, Germeen NS Girgis. Formulation and Physical Characterization of a Novel Sustained-Release Ophthalmic Delivery System for Sparfloxacin: the Effect of the Biological Environment. Ophthalmology Research: An International Journal. 2013;1(1):1-22.

24. Gratieri T, Gelfuso G, Rocha E, Sarmento V, Freitas O, Lopez R. A poloxamer/chitosan in situ forming gel with prolonged retention time for ocular delivery. Eur J Pharm Biopharm. 2010;75(2):186-193. doi: 10.1016/j.ejpb.2010.02.011

25. Indian Pharmacopoeia.2010. The Controller of Publications, Delhi, India.

26. Jain GK, Pathan SA, Akhter S, Jayabalan N, Talegaonkar S, Khar RK, et.al. Microscopic and spectroscopic evaluation of novel PLGAchitosan Nanoplexes as an ocular delivery systems. Colloids and Surf B Biointerfaces. 2011;82:397-403. doi: 10.1016/j.colsurfb.2010.09.010. 